\title{
COMPARATIVE EVALUATION OF THE EFFICACY OF Pseudomonas putida IN THE BIOREMEDIATION OF DIESEL FUEL CONTAMINATED DERNO-PODZOLUIVISOLIC SOIL OF DIFFERENT HORIZONS
}

\section{OLATUNBOSUN OLAWOYE ALONGE}

(Received 20 May 2016; Revision Accepted 19 July 2016)

\begin{abstract}
This study was carried out to compare the efficacy of Pseudomonas putida, contained in the biopreparation «Pseudomin» in the bioremediation of diesel fuel contaminated derno-podzoluivisolic soil of two different horizons. By analyzing the Total Petroleum Hydrocarbons (TPH) content using IR-spectrometry method under laboratory conditions, results of the research showed that the inoculation of Pseudomonas putida in to the diesel fuel contaminated derno-podzoluivisolic soil samples in only 12 weeks was able to reduce the diesel fuel content up to $99.2 \%$ in the humus-accumulative horizon; and up to $92.8 \%$ in the eluvial horizon. Comparative evaluation of the contaminated variants inoculated with Pseudomonas of both horizons revealed a significantly higher rate of diesel fuel degradation in the humus accumulative horizon of up to 8.7 times, compared to the eluvial horizon, which shows a slightly slower rate of degradation.
\end{abstract}

KEYWORDS: Bioremediation, petroleum hydrocarbon, humus-accumulative horizon, eluvial horizon, dernopodzoluivisolic soil, Pseudomonas putida, biological preparation «Pseudomin»,

\section{INTRODUCTION}

The problem of oil spill is one of the major challenges of modern ecology [Atlas, 1988; Bola et al, 2006; Halimov et al, 1996; Stankevich, 2002]. In recent years, due to the increase in the production of oil, construction of new oil pipelines and refineries, there has been a sharp increase in the occurrence and scale of crude oil contamination, leading to a shift in the ecological balance, and the deterioration of the environment [Atlas, 1988; Nwachukwu, 2001; Stankevich, 2002; Vasenev et al, 2010].

With an annual volume of world crude oil production of more than 2.5 billion tons, about 50 million tons of crude oil per year is lost to the environment as a result of accidents, leaks, bunkering, etc. Creating serious environmental challenges in many countries including Nigeria and Russia [Atlas, Bartha, 1992; Bola et al, 2006; International Petroleum Monthly, 2011].

The bioremediation of petroleum hydrocarbon contaminated soils using petroleum hydrocarbonoxidizing microorganisms is presently accepted worldwide as the most cost effective and environmental friendly means of cleaning up oil contaminated soil and water [Kireeva, 1996; Stankevich, 2002; Tyagi, 2010; Vidali, 2001].

Bio-augmentation, which is one of the techniques of bioremediation, involves the introduction / inoculation into the contaminated medium of a single / consortium of highly specialized petroleum hydrocarbonoxidizing microorganisms in the form of biological preparations, one of which is Pseudomin [Nwachukwu, 2001; Stankevich, 2002].

Pseudomin was developed at the Department of
Microbiology of the Russian State Agrarian University MTAA named after K.A. Timiryazev, using strains of petroleum hydrocarbon-oxidizing microorganisms of the genus of Pseudomonas putida, isolated from dernopodzoluivisolic soils long exposed to contamination near a filling station. Pseudomin possesses a prolonged degrading effect on petroleum products remaining in the soil after mechanical and (or) physical-chemical treatment. It has been successfully tested under conditions of the southern taiga zone of the European part of Russia and in a number of oil fields in Siberia [Stankevich, 2002].

However, little research has been carried out on its efficacy in the bioremediation of petroleum hydrocarbon contaminated soils of different horizons, hence the aim of the research - to make comparative assessments on the efficacy of Pseudomin in the bioremediation of diesel contaminated humicaccumulative $\left(A_{1}+A_{1} A_{2}\right)$ and eluvial $\left(A_{2}\right)$ horizons of derno-podzoluivisolic soils of the central region of Russia.

\section{MATERIALS AND METHODS OF RESEARCH}

Materials for this research included:

1. Soil sample: mixed samples of the humicaccumulative and transition horizons $\left(A_{1}+A_{1} A_{2}\right)$; and samples from the eluvial $\left(A_{2}\right)$ horizons of a loamy, completely podzolized dernopodzoluivisols, were collected for the research. The samples were collected from Area 3, of the ecological monitoring site, located in the experimental forest reserve of the Russian State Agrarian University - MTAA named after K.A. Timiryazev 
Table 1: Summary of the properties of the understudy derno-podzoluivisolic soil of different horizons [Burinova, 2011]

\begin{tabular}{|c|c|c|c|c|c|c|}
\hline $\begin{array}{l}\text { Topography and location } \\
\text { (coordinates) of the area } \\
\text { of sample collection }\end{array}$ & Horizon & Depth & $\mathrm{C}_{\text {org }}, \%$ & $\mathrm{pH}_{\mathrm{H} 2 \mathrm{O}}$ & $\mathrm{pH}_{\mathrm{KCL}}$ & $\begin{array}{l}\mathrm{H}, \mathbf{m g -} \\
\text { eqv/100g } \\
\text { soil }\end{array}$ \\
\hline \multirow{2}{*}{$\begin{array}{l}\text { Watershed of the moraine } \\
\text { hills } \\
\text { (N55 } 45^{\circ} 49^{\prime} 11.8^{\prime \prime} \\
\left.\text { E037 } 33^{\prime} 08.6^{\prime \prime}\right)\end{array}$} & $A_{1}+A_{1} A_{2}$ & $0-30$ & 1,91 & 4,21 & 3,81 & 12,80 \\
\hline & $\mathrm{A}_{2}$ & $30-44$ & 0,31 & 4,32 & 4,93 & 8,50 \\
\hline
\end{tabular}

2. Pollutant: Diesel fuel was used as a contaminant in the model laboratory experiments, which had a density of about 840 $\mathrm{kg} / \mathrm{m}^{3}$. With boiling point of $40^{\circ} \mathrm{C}$; and freezing point $-35^{\circ} \mathrm{C}$.

3. Microorganism: For this study pure culture strains of petroleum hydrocarbon oxidizing microorganisms were used, which belong to the genus Pseudomonas putida, strain 91-96 (first isolated from oil contaminated dernopodzoluivisolic soils by the Department of Microbiology and Immunology of the Russian State Agrarian University - MTAA named after K.A. Timiryazev).

\section{Methods of research:}

To conduct this study, analysis of the Total Petroleum Hydrocarbons (TPH) content using IRspectrometry method on a liquid photometric analyzer «Model №: Fluorat-02» instrument, was carried out at regular intervals [PND F 16.1; 2.2.22-98, 2001].

The research was carried out in the laboratory of the agro-ecological monitoring, modeling and ecosystems forecasting; and in the microbiology laboratory of the Russian State Agrarian University-
MTAA named after K.A. Timiryazev. Statistical analysis of the research results were performed by «Statistic 8.0».

\section{Experimental Design:}

The two horizons (humus-accumulative and eluvial) of the understudy derno-podzoluivisolic soil having been dried and sieved (through hand held sieves with diameter of $1 \mathrm{~mm}$ ) were placed into 2 different containers for mixing. $2.7 \mathrm{~kg}$ of soil was placed in each bucket.

According to the experimental scheme, the variants to be contaminated were polluted by the addition of diesel fuel at a concentration of $18.2 \mathrm{mg} / \mathrm{g}$ soil, which corresponds to $5 \%$ by weight of air-dry soil. In the variants to be inoculated with hydrocarbon oxidizing microorganism, a $10 \mathrm{ml}$ suspension of Pseudomonas putida was added, with titer value of 1.6 $\times 10^{7} \mathrm{CFU} / \mathrm{ml}$.

Finally the soil was mixed and placed in plastic containers of $270 \mathrm{~g}$ each, the Total number of experimental variants -8 , replications -3 (tab. 2). The soil moisture content was fixed at $60 \%$, and maintained daily by gravimetrical methods.

Table 2: Experimental Scheme

\begin{tabular}{|l|l|l|}
\hline \multirow{2}{*}{$\begin{array}{l}\text { No of } \\
\text { Variant }\end{array}$} & Experimental Series (derno-podzoluivisolic soil) \\
\cline { 2 - 3 } & Horizon $\mathbf{A}_{\mathbf{1}}+\mathbf{A}_{\mathbf{1}} \mathbf{A}_{\mathbf{2}}$ & Horizon $\mathbf{A}_{\mathbf{2}}$ \\
\hline 1 & Uncontaminated soil & Uncontaminated soil \\
2 & Contaminated Soil & Uncontaminated Soil \\
3 & Uncontaminated soil + Pseudomonas & Contaminated Soil + Pseudomonas \\
4 & Contaminated Soil + Pseudomonas & \multicolumn{2}{|l}{} \\
\hline
\end{tabular}

\section{RESULTS}

Analysis of the total petroleum content in the two horizons of the understudy derno-podzoluivisolic soil is displayed in the table below: 
Table 3: The rate of diesel fuel degradation in the understudy derno-podzoluivisolic soil of different horizons

\begin{tabular}{|c|c|c|c|c|c|c|c|c|c|c|}
\hline \multirow{2}{*}{\multicolumn{3}{|c|}{ Experimental Variants }} & \multirow{2}{*}{ 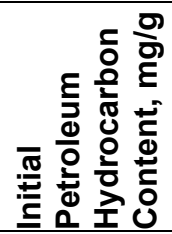 } & \multirow{2}{*}{ 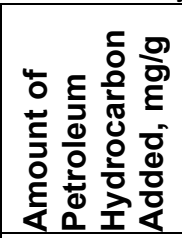 } & \multicolumn{6}{|c|}{$\begin{array}{l}\text { Total Petroleum Hydrocarbon, mg/g } \\
\text { (Weeks) }\end{array}$} \\
\hline & & & & & 1 & 2 & 3 & 4 & 9 & 12 \\
\hline \multirow[b]{2}{*}{ 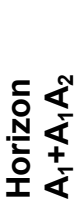 } & 1 & Contaminated Soil & \multirow[b]{2}{*}{0.01} & \multirow[b]{2}{*}{18.2} & 8.54 & 7.02 & 5.01 & 3.16 & 0.76 & 0.34 \\
\hline & 2 & $\begin{array}{l}\text { Contaminated Soil + } \\
\text { Pseudomonas }\end{array}$ & & & 7.25 & 6.15 & 4.75 & 2.58 & 0.57 & 0.15 \\
\hline \multirow[b]{2}{*}{ 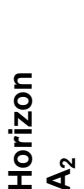 } & 3 & Contaminated Soil & \multirow[b]{2}{*}{0.01} & \multirow[b]{2}{*}{18.2} & 11.39 & 9.49 & 7.90 & 6.32 & 3.02 & 1.87 \\
\hline & 4 & $\begin{array}{l}\text { Contaminated Soil + } \\
\text { Pseudomonas }\end{array}$ & & & 10.75 & 9.14 & 7.55 & 5.72 & 2.59 & 1.31 \\
\hline \multicolumn{3}{|c|}{ Approximate Safe Exposure Level } & \multicolumn{2}{|l|}{$4 \mathrm{mg} / \mathrm{g}$} & & & & & & \\
\hline
\end{tabular}

\section{DISCUSSIONS}

The scale of soil pollution by crude oil and its derivatives sometimes reaches several lower layers of the soil profile, bringing about the destruction of the soil's properties and ecological balance, therefore, it is necessary to study and evaluate the effectiveness of the biological preparation Pseudomin in the clean-up of oil contaminated soils of different horizons. To carry out this experiment, the humus-accumulative $\left(A_{1}+A_{1} A_{2}\right)$, and eluvial $\left(A_{2}\right)$ horizons of derno-podzoluivisolic soil were used.

After only 12 weeks of experiment, results of the research on the effectiveness of the biological preparation Pseudomin in the clean-up of oil contaminated humus-accumulative $\left(A_{1}+A_{1} A_{2}\right)$, and eluvial $\left(A_{2}\right)$ horizons of derno-podzoluivisolic soil, revealed a sharp decline in the total petroleum hydrocarbon content in the soils contaminated by diesel fuel of up to 25-48 times the initial amount after the $1^{\text {st }}$ week of experiment in the mixed sample of horizons $A_{1}+A_{1} A_{2}$; and up to 6-8 times the initial amount after the $1^{\text {st }}$ week of experiment in the soil sample from horizon $\mathrm{A}_{2}$ (tab. 3).
As reported by many researchers in their studies [Halimov et al, 1996; Kireeva, 1996; Stankevich, 2002], the initial stage of the bioremediation process of diesel fuel contaminated soils, is characterized by the evaporation of the volatile fractions (light fraction of petroleum hydrocarbons) as a result of physical and chemical weathering and evaporation, i.e. about $50 \%$ of diesel fuel decomposes without the action of hydrocarbon oxidizing microorganisms. This trend was also observed in all the variants of the experiment, i.e., by comparing the residual petroleum hydrocarbon content at the $1^{\text {st }}$ week of the experiment to the total amount of diesel fuel added, about half the content had already evaporated.

Comparative evaluation of the contaminated variants inoculated with Pseudomonas of both horizons (variants $2 \& 4$ ) reveals a significantly higher rate of diesel fuel degradation in the humus accumulative horizon of up to 8.7 times, compared to the eluvial horizon, which shows a slightly slower rate of degradation. This phenomenon can be explained by the presence of humus, which provides an additional source of energy (co-substrate), for the soil microbial communities, thus increasing their population and microbial activity (Figure 1 ). 


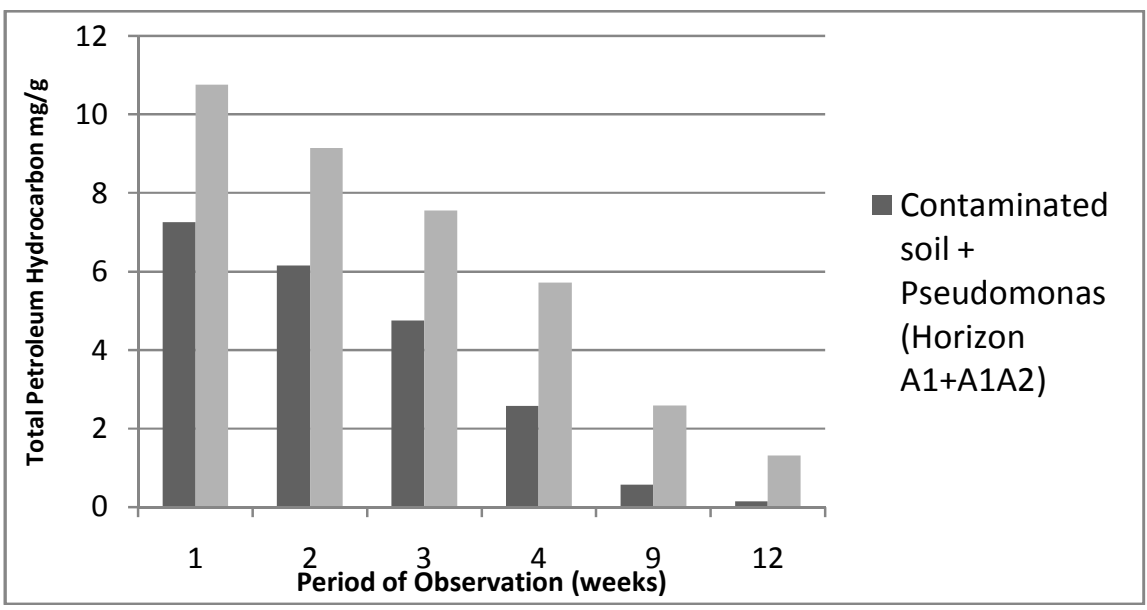

Fig. 1: Graphical representation of the efficacy of Pseudomin in the bioremediation of the diesel contaminated dernopodzoluivisols of two different horizons

It should also be noted that results of the experiment showed a significant difference in the rate of decomposition of diesel fuel between the variants with the inoculation of Pseudomonas putida (variants $2 \& 4$ ) and without inoculation (variants $1 \& 3$ ). The inoculated variants showed the most impressive result in the reduction of the amount of diesel fuel, as the residual content of petroleum hydrocarbon at the $12^{\text {th }}$ week of experiment was 2.3 times lower in the case of the humus accumulative horizon; and 1.4 times lower in the eluvial horizon, when compared with the variants without inoculation, This provides evidence of the potency of the biological product (Pseudomin) in accelerating the decomposition of petroleum products in the soil, at an average of 1.9 times

The substantial decrease in the total petroleum hydrocarbon content observed in the variants without the inoculation of Pseudomonas putida (variants $1 \& 3$ ), was as a result of the conducive environment created for the indigenous microbial community (biostimulation), by the constant action of stirring (ploughing) of soil samples in the containers, which improved the aeration and percolation of the soil; as well the constant monitoring of the soil moisture content.

In general, results of the experiment have shown a very high efficacy and potency of the Pseudomonas putida contained in the biological product Pseudomin in the biodegradation of petroleum hydrocarbons, as evident in the over-all scale of total hydrocarbon reduction in the experimented soils, where in only 12 weeks the inoculation of Pseudomin into the derno-podzoluivisolic soil samples, was able to reduce the diesel fuel content in the: humus-accumulative horizons up to $99.2 \%$, showing a $1.1 \%$ increase over the non-inoculated variant, which had an efficiency rate of $98.1 \%$. While the efficiency rate of the non-inoculated variant was quite significant, as a result of biostimulation, the addition of Pseudomin had a more impressive impact on the rate of degradation, which was 2.3 times faster as evidenced by the residual petroleum hydrocarbon content at the $12^{\text {th }}$ week of experiment. The residual amounts of petroleum hydrocarbon in the soil after the experiment were significantly lower than the approximate safe exposure levels for soils of the mid and southern taiga of Russia [Russian State Epidemiological Sanitary Standard .2.1.7. Soil, 2010].

In the eluvial horizon, the rate of efficiency for the inoculated variant was $92.8 \%$, showing a $3.1 \%$ increase over the non-inoculated variant, which had an efficiency rate of $89.7 \%$.

Cost-wise the inoculation of Pseudomonas putida contained in the biological product Pseudomin into the soil is minimal, as pure culture strains of Pseudomonas putida can be directly introduced into the soil, at no significant cost.

In conclusion the application of bioaugmentation as a technique of bioremediation using pure culture strains of Pseudomonas putida has proven to be very effective and efficient for the clean-up of petroleum hydrocarbon contaminated soils of various horizons of the soil profile and can be used for the bioremediation of petroleum hydrocarbon contaminated soils no matter the depth and scale of pollution provided all other factors are optimal.

\section{ACKNOWLEDGEMENT}

The author will like to thank and appreciate the supervisory role and support of Professor Vasenev I.I., and Dr. Selitskaya O.V., of the Russian State Agrarian University-MTAA named after K.A. Timiryazev, in the completion of this work.

\section{REFERENCES}

Atlas, R. M., 1988. Biodegradation of hydrocarbons in the environment // Environmental biotechnology. - ed. G.S. Omenn Plenum. Press. - N.Y. - P. 200-222.

Atlas, R. M and Bartha, R., 1992. Hydrocarbon biodegradation and oil spill bioremediation (ed. by K.C. Marshall) // Adv. Microb. Ecol. - V. 12. P. 287-338.

Bola O. Oboh., Matthew O. Ilori., Joseph O. Akinyemi and Sunday A. Adebusoye., 2006. Hydrocarbon Degrading Potentials of Bacteria Isolated from a 
Nigerian Bitumen (Tarsand) Deposit. Nature and Science. 4, (3): 51-57.

Burinova, B. V., 2011. Ecological evaluation of the spatial and temporal variability of the heavy metal content of the soils of the experimental forest reserve of the Russian State Agrarian University - MTAA named after K.A. Timiryazev /l. Ph.D. Dissertation synopsis. -Moscow, - 25 p.

Halimov, E. M., Levin, S. V and Guseev, S. V., 1996. Ecological and microbiological aspects of the damaging effect of oil on the properties of soil // Bulletin. Moscow State University. - Ser. 17. Soil Science, № 2. - P. 59-64.

Kireeva, N. A., 1996. Biodegradation of crude oil pollutants in soil using cultures of hydrocarbonoxidizing microorganisms // Biotechnology, № 1. - P. 51-54.

Nwachukwu, S. C. U., 2001. Bioremediation of sterile agricultural soils polluted with crude petroleum by application of the soil bacterium, Pseudomonas putida, with inorganic nutrient supplementations. Curr Microbiol,; 42, (2): 231236.

Stankevich, D. S., 2002. Using hydrocarbon oxidizing bacteria of the genus Pseudomonas putida for the bioremediation of oil-contaminated soils. Ph.D. Dissertation. - Moscow, P. 189.
Tyagi, M., da Fonseca, M. R and de Carvalho, C. C. C. R., 2010. Bioaugmentation and biostimulation strategies to improve the effectiveness of bioremediation processes // Biodegradation. 22, (2): 231-241.

Vasenev, I. I., Buzylev, A. V., Kurbatova, Y. A., Rudnev, N. I and Chistotin, M. V., 2010. Agroecological modeling and design. M.: RSAU-MTAA, P. 260

Vidali, M., 2001. Bioremediation: An overview // Pure Applied Chemistry. V. 73 № 7. - P. 1163-1172.

International Petroleum Monthly (IPM)., 2011. URL Source: $\quad$ http://www.eia.gov/ipm/supply.html (date accessed 27.10.2012).

PND F 16.1; 2.2.22-98 Method of measuring the mass fraction of petroleum products in mineral, organogenic, and organic mineral soils. State report «On the condition and protection of the environment of the Russian Federation», 2001.

Russian State Epidemiological Sanitary Standard.2.1.7. Soil, urban center cleaning, household and industrial waste. Approximate Safe Exposure Level for oil and petroleum products in the soil. (Draft) Official publication. - M. 2000. 